\title{
Diet, lung function, and lung function decline in a cohort of 2512 middle aged men
}

\author{
Barbara K Butland, Ann M Fehily, Peter C Elwood
}

\begin{abstract}
Background-A prospective cohort study of 2512 Welshmen aged 45-59 living in Caerphilly in 1979-1983 was used to investigate associations between diet and lung function.

Methods-At baseline (phase I) and at five year follow up (phase II), forced expiratory volume in one second $\left(F E V_{1}\right)$ was measured using a McDermott spirometer and dietary data were obtained using a semi-quantitative food frequency questionnaire.
\end{abstract}

Results-Good lung function, indicated by high maximum $\mathrm{FEV}_{1}$ given age and height, was associated with high intakes of vitamin $C$, vitamin $E$, $\beta$-carotene, citrus fruit, apples, and the frequent consumption of fruit juices/squashes. Lung function was inversely associated with magnesium intake but there was no evidence of an association with fatty fish. Following adjustment for confounders including body mass index, smoking history, social class, exercise, and total energy intake, only the associations with vitamin $E$ and apples persisted, with lung function estimated to be $39 \mathrm{ml}(95 \%$ confidence interval (CI) 9 to 69) higher for vitamin $E$ intakes one standard deviation (SD) apart and $138 \mathrm{ml}$ higher (95\% CI 58 to 218$)$ for those eating five or more apples per week compared with non-consumers. Decline in lung function between phases was not significantly associated with the changing intakes of apples or vitamin E. An association between high average apple consumption and slow decline in lung function lost significance after adjustment for confounders.

Conclusions-A strong positive association is seen between lung function and the number of apples eaten per week cross sectionally, consistent with a protective effect of hard fruit rather than soft/citrus fruit. The recent suggestion that such effects are reversible was not supported by our longitudinal analysis.

(Thorax 2000;55:102-108)

Keywords: diet; lung function; apples

The association between lung function, respiratory symptoms, and diet has received considerable attention in recent years and has even been put forward as a possible explanation for recent rises in the prevalence of asthma both in Britain and other countries. ${ }^{1}$ Several hypotheses have arisen, in particular those based on the biological premise that antioxidants in food may protect the lungs against oxidant attack from known irritants such as ozone, ${ }^{2}$ nitrogen dioxide, ${ }^{3}$ and cigarette smoke. ${ }^{4}$

Positive associations between lung function in adults and antioxidant vitamins have been demonstrated cross sectionally by several epidemiological studies. ${ }^{5-12}$ These relate mainly to vitamin $C,^{57-911} 12$ although some studies have reported associations with vitamin $\mathrm{E}^{710}$ and $\beta$-carotene. ${ }^{12}{ }^{13}$ Positive associations between lung function and eating fresh fruit have also been reported using data from the Health and Lifestyle Surveys ${ }^{6}{ }^{14}$ and the Ten Towns Study. ${ }^{15}$ Whether fresh fruit is acting as a marker for one or more of the aforementioned vitamins is unclear, and it has been suggested that other antioxidants-notably flavonoids (vitamin P) found in hard fruit such as apples-might be important. ${ }^{16}$ An association between change in fresh fruit intake and change in lung function was recently reported in a longitudinal analysis of the Health and Lifestyle Surveys. ${ }^{14}$ Based on these results, Carey et $a l^{14}$ not only postulated a protective effect for fresh fruit on lung function but also suggested that such effects were totally reversible and not progressive.

Other food sources which may have a protective effect on lung function for reasons other than antioxidant content include omega-3 fatty acids such as eicosapentaenoic acid found in fatty fish, which may protect against allergic sensitisation by inhibiting the production of prostaglandin $\mathrm{E}_{2},{ }^{17}$ and magnesium which is thought to be influential in protecting the airways against bronchoconstriction and inflammation. ${ }^{18} 19$

Data from the Caerphilly heart disease study which included lung function measures and dietary questionnaire data collected both at baseline (phase I) and at five year follow up $(\text { phase II })^{20}$ provided an ideal opportunity to investigate some of these hypotheses further in a large cohort of middle aged men.

\section{Methods}

PHASE I

All men aged 45-59 years and living in Caerphilly or one of five surrounding villages were invited to attend an evening clinic. Clinics were run between 1979 and 1983. From the 2818 eligible men contacted, 2512 (89\%) agreed to take part. Information on occupation, smoking, and physical activity both at work and during leisure time was obtained using interviewer administered questionnaires. Social class was recorded according to the Registrar General's 1980 classification of 
occupations. $^{21}$ Height in bare feet was measured in mm using the Holtain stadiometer and weight in light clothes was measured in $\mathrm{kg}$ using scales. Lung function tests were performed using a McDermott spirometer. After a demonstration, each man was asked to perform the test until three technically satisfactory readings were obtained. Dietary data were collected using a self-administered semiquantitative food frequency questionnaire which, after some initial instruction, the men took home and completed with the help of their spouse. $^{20}$

PHASE II

After a period of five years the cohort was contacted again and asked to attend a second evening clinic. Dietary data were collected using a slightly different version of the self-administered semi-quantitative food frequency questionnaire and completed questionnaires were checked through with the subject, usually by a dietitian/nutritionist. Men were asked again about their smoking history. Respiratory function tests were performed as in phase I but administered by a doctor rather than an interviewer and weight in light clothes was measured in $\mathrm{kg}$ using a beam balance. ${ }^{20}$

DIETARY DATA

Food and nutrient intakes were assessed by the semi-quantitative food frequency questionnaires. These contained questions about the frequency of consumption (number of times per week at phase I and number of days per week at phase II) of a large number of foodstuffs normally eaten as part of the UK diet. For some foods questions were asked about the quantity consumed-for example, the number and size of slices of bread, the amount of milk consumed per day, the number of eggs eaten per week, the amount of butter/margarine consumed per week. For other foods such as meat and fish, quantities were assessed by combining frequency information with average portion size. ${ }^{20}$

The average portion sizes used in this study were calculated from seven day weighed dietary records completed by a one third systematic sample of the Caerphilly cohort at phase I. A comparison of nutrient intakes for the first 119 of these men, as calculated from their weighed dietary records versus their phase I food frequency questionnaires, has been published elsewhere. ${ }^{22}$

The semi-quantitative food frequency questionnaires from phase I and phase II were used to assess intakes of vitamin $\mathrm{C}$, vitamin $\mathrm{E}$, $\beta$-carotene, and magnesium. The questionnaires differed slightly between phases, particularly in the way they recorded fats, cakes, and tinned fruit, but both asked about the number of apples eaten per week, the number of oranges or grapefruit eaten per week, the frequency of drinking fruit juices and squashes, and the frequency of eating fatty fish (including kippers, herring, pilchards, tuna, sardines and salmon).
STATISTICAL METHODS

Multiple regression models were fitted using Stata $^{23}$ to investigate associations of dietary factors (explanatory variables) with maximum $\mathrm{FEV}_{1}$ (dependent variable). The dietary factors considered were vitamin $\mathrm{C}$, vitamin $\mathrm{E}$, $\beta$-carotene, magnesium, apples, citrus fruit (oranges or grapefruit), and intake frequencies for fatty fish and fruit juices/squashes. By including additional variables in the regression models, all associations were initially adjusted for age, height, age $\mathrm{e}^{2}$, and height ${ }^{2}$ and subsequently for the confounding effects of body mass index, smoking, social class, work exercise, leisure exercise, and total energy intake. Smoking was entered into models as one eightlevel factor (never smoked, ex-smoker for $<1$ year, ex-smoker for 1-4 years, ex-smoker for $5-9$ years, ex-smoker for $\geqslant 10$ years, cigar/pipe smoker, cigarette smoker, mixed smoker) and three continuous variables (number of cigarettes currently smoked per day, number of cigars currently smoked per day, and number of ounces of tobacco currently smoked per week). Separate analyses within smoking subgroups (never smoked, ex-smoker, cigar/pipe smoker, cigarette smoker) were also conducted due to the prior hypothesis that the protective effects of antioxidant vitamins and antioxidant rich foods would be stronger among smokers.

For each dietary factor that appeared to be related to lung function cross sectionally, change in that factor between phases was investigated as a predictor of change in maximum $\mathrm{FEV}_{1}$ over the same period. Associations were modelled using multiple regression in Stata $^{23}$ adjusting initially for average age, average age squared, height, and height squared and subsequently for average body mass index, change in body mass index, "average" smoking, change in smoking, social class at phase I, work exercise at phase I, leisure exercise at phase I, average energy intake, and change in energy intake. "Average" smoking was entered into the model as one seven-level factor and three continuous variables while change in smoking was entered as a nine-level factor and three continuous variables. Different lengths of follow up were adjusted for by modelling change in $\mathrm{FEV}_{1}$ per year, then multiplying predicted values by 5 .

\section{Results}

The cohort consisted of 2512 middle aged men of mean (SD) age 52.1 (4.6) years of whom $55 \%$ were current smokers and $29 \%$ were ex-smokers, with $66 \%$ employed in manual occupations. The estimated mean (SD) daily intakes of vitamin $\mathrm{C}$, vitamin $\mathrm{E}, \beta$-carotene, and magnesium were $51.4(20.7) \mathrm{mg} /$ day $(\mathrm{n}=$ 2414), 5.1 (2.0) mg/day ( $\mathrm{n}=2389), 2625$ $(1682) \mu \mathrm{g} /$ day $(\mathrm{n}=2293)$, and 264.7 $(87.6) \mathrm{mg} /$ day $(\mathrm{n}=2334)$, respectively. At least one $\mathrm{FEV}_{1}$ reading was provided by 2406 men at phase I (2162 provided three readings) and 1890 men at phase II (1870 provided three readings), with information at both phases provided by 1827 men. Using all available readings the mean (SD) maximum $\mathrm{FEV}_{1}$ at phase I was 2752 (762) $\mathrm{ml}$ with change in 
Table 1 Cross sectional analysis: difference in forced expiratory volume in one second (FEV) in ml associated with a one standard deviation increase in nutrient intake at phase I

\begin{tabular}{|c|c|c|c|c|c|c|c|c|}
\hline \multirow[t]{2}{*}{ Adjusted for } & \multicolumn{2}{|c|}{ Vitamin $C(n=2136)$} & \multicolumn{2}{|c|}{ Vitamin $E(n=2136)$} & \multicolumn{2}{|c|}{ Magnesium $(n=2136)$} & \multicolumn{2}{|c|}{$\beta$-carotene $(n=2035)$} \\
\hline & Difference & $95 \% C I$ & Difference & $95 \% C I$ & Difference & $95 \% C I$ & Difference & $95 \% C I$ \\
\hline (1) Age, height, age ${ }^{2}$, height $^{2}$ & $67.8^{\star \star \star}$ & 39.6 to 96.1 & $37.9^{\star \star}$ & 9.3 to 66.6 & $-31.8^{\star}$ & -60.0 to -3.5 & $31.9^{\star}$ & 2.9 to 60.8 \\
\hline (2) Model $1+$ body mass index & $65.0^{\star \star \star}$ & 36.8 to 93.1 & $37.0^{\star}$ & 8.4 to 65.5 & $-32.4^{\star}$ & -60.5 to -4.3 & $29.5^{\star}$ & 0.6 to 58.3 \\
\hline (3) Model $2+$ smoking history & $37.3^{\star \star}$ & 9.5 to 65.1 & 23.2 & -4.5 to 50.9 & $-31.5^{\star}$ & -58.8 to -4.3 & 14.3 & -13.9 to 42.4 \\
\hline (4) Model $3+$ social class & 21.1 & -6.8 to 49.0 & 19.7 & -7.8 to 47.2 & $-31.1^{\star}$ & -58.2 to -4.1 & 11.2 & -16.7 to 39.1 \\
\hline $\begin{array}{l}\text { (5) Model } 4+\text { work exercise and leisure } \\
\text { exercise }\end{array}$ & 16.2 & -11.6 to 44.0 & 14.0 & -13.4 to 41.4 & $-35.4^{\star}$ & -62.4 to -8.5 & 7.4 & -20.4 to 35.3 \\
\hline (6) Model $5+$ total energy intake & 26.2 & -2.0 to 54.4 & $39.1^{\star \star}$ & 9.4 to 68.8 & -2.7 & -41.1 to 35.6 & 14.1 & -13.9 to 42.1 \\
\hline
\end{tabular}

${ }^{\star} \mathrm{p}<0.05,{ }^{\star \star} \mathrm{p}<0.01,{ }^{\star \star \star} \mathrm{p}<0.001$.

maximum $\mathrm{FEV}_{1}$ between phases averaging -19 (368) $\mathrm{ml}$. Changes in vitamin $\mathrm{C}$ and vitamin $\mathrm{E}$ intakes between phases averaged -2.0 (22.6) $\mathrm{mg} /$ day $(\mathrm{n}=1894)$ and $-0.1(2.1) \mathrm{mg} /$ day $(n=1878)$, respectively.

\section{CROSS SECTIONAL ANALYSIS}

Lung function measured as maximum $\mathrm{FEV}_{1}$ was positively associated with vitamin $C$, vitamin $E$, and $\beta$-carotene $(p<0.001, p=$ $0.009, \mathrm{p}=0.031$, respectively; table 1 ). However, regression coefficients, though essentially unconfounded by body mass index, were substantially reduced in magnitude and lost significance following adjustment for smoking and social class $(\mathrm{p}=0.137, \mathrm{p}=0.160, \mathrm{p}=$ 0.431 , respectively; table 1 ). The size and significance of the association between lung function and vitamin $\mathrm{E}$ was restored following additional adjustment for total energy intake $(\mathrm{p}<0.01)$ with lung function estimated to be $39.1 \mathrm{ml}$ (95\% confidence interval (CI) 9.4 to 68.8) higher for vitamin $\mathrm{E}$ intakes one standard deviation ( $2 \mathrm{mg} /$ day) apart (table 1). This reduced slightly to $31.7 \mathrm{ml}$ (95\% CI 0.9 to 62.5) following additional adjustment for vitamin $\mathrm{C}$ and the frequency of apple intake.
There was a significant negative association between magnesium and lung function ( $\mathrm{p}=$ 0.028 ) which appeared unconfounded by body mass index, smoking, social class, or exercise but completely disappeared following additional adjustment for total energy intake $(\mathrm{p}=$ 0.888; table 1 ).

Lung function was positively associated with frequent consumption of citrus fruit, fruit juices/squashes, and apples ( $\mathrm{p}=0.004, \mathrm{p}=$ $0.012, \mathrm{p}<0.001$, respectively). The associations with citrus fruit and fruit juices/squashes lost significance following adjustment for smoking but the association with apples persisted even following additional adjustment for body mass index, social class, exercise, and total energy intake (table 2). Regression coefficients suggested that lung function was $138.1 \mathrm{ml}(95 \%$ CI 58.1 to 218.1) higher for those eating five or more apples per week compared with nonconsumers (table 2). This reduced slightly to $115.3 \mathrm{ml}$ (95\% CI 30.6 to 200.0) following adjustment for vitamins $\mathrm{C}$ and $\mathrm{E}$.

There was a significant negative association between total energy intake and lung function which persisted after adjustment for confounding $(\mathrm{p}<0.001)$. Regression coefficients suggested lung function was $48.8 \mathrm{ml}(95 \%$ CI

Table 2 Cross sectional analysis: differences in forced expiratory volume in one second (FEV, in ml associated with increases in the frequency of food intake from baseline category at phase I

\begin{tabular}{|c|c|c|c|c|c|}
\hline \multirow[t]{2}{*}{ Food } & \multirow[t]{2}{*}{ No. } & \multicolumn{4}{|l|}{ Adjusted for: } \\
\hline & & $\begin{array}{l}\text { (1) Age, height, age }{ }^{2} \text { and } \\
\text { height }^{2}\end{array}$ & $\begin{array}{l}\text { (2) Model } 1+\text { body mass } \\
\text { index and smoking }\end{array}$ & $\begin{array}{l}\text { (3) Model } 2+\text { social class, } \\
\text { work exercise and leisure } \\
\text { exercise }\end{array}$ & $\begin{array}{l}\text { (4) Model } 3+\text { total energy } \\
\text { intake }\end{array}$ \\
\hline \multirow{2}{*}{\multicolumn{6}{|c|}{ Fatty fish (no. of times per week) }} \\
\hline & & & & & \\
\hline Never/rarely & 709 & 0 (baseline) & 0 (baseline) & 0 (baseline) & 0 (baseline) \\
\hline$<1$ & 669 & $28.0(-42.3$ to 98.4$)$ & $20.4(-47.5$ to 88.4$)$ & $5.7(-61.4$ to 72.7$)$ & $9.0(-57.9$ to 75.8$)$ \\
\hline 1 & 543 & $-33.1(-107.5$ to 41.3$)$ & $-21.4(-93.3$ to 50.5$)$ & $-28.9(-99.9$ to 42.0$)$ & $-15.3(-86.5$ to 56.0$)$ \\
\hline$\geqslant 2$ & 107 & $29.4(-105.9$ to 164.7$)$ & $56.8(-73.8$ to 187.5$)$ & $7.4(-121.7$ to 136.5$)$ & $32.7(-96.9$ to 162.4$)$ \\
\hline Test for trend ${ }^{\star}$ & & $\mathrm{p}=0.572$ & $\mathrm{p}=0.926$ & $\mathrm{p}=0.503$ & $\mathrm{p}=0.851$ \\
\hline \multicolumn{6}{|c|}{ Citrus fruit (no. of grapefruit or oranges per week) } \\
\hline None & 1125 & 0 (baseline) & 0 (baseline) & 0 (baseline) & 0 (baseline) \\
\hline 1 & 368 & $82.9(4.4$ to 161.4$)$ & $52.7(-23.2$ to 128.6$)$ & $33.1(-41.7$ to 107.9$)$ & $36.0(-38.5$ to 110.6$)$ \\
\hline $2-4$ & 491 & $5.6(-65.2$ to 76.4$)$ & $-31.0(-99.4$ to 37.5$)$ & $-48.5(-116.0$ to 19.0$)$ & $-40.2(-107.5$ to 27.2$)$ \\
\hline$\geqslant 5$ & 117 & $209.5(82.8$ to 336.2$)$ & $123.0(-0.3$ to 246.4$)$ & $99.3(-22.1$ to 220.7$)$ & $105.4(-15.6$ to 226.4$)$ \\
\hline Test for trend $\dagger$ & & $\mathrm{p}=0.004$ & $\mathrm{p}=0.228$ & $\mathrm{p}=0.513$ & $\mathrm{p}=0.393$ \\
\hline \multicolumn{6}{|c|}{ Fruit juice (no. of times per week) } \\
\hline Never/rarely & 519 & 0 (baseline) & 0 (baseline) & 0 (baseline) & 0 (baseline) \\
\hline$<1$ & 303 & $125.7(31.2$ to 220.1$)$ & $88.9(-2.7$ to 180.6$)$ & $53.5(-37.0$ to 144.0$)$ & $54.3(-36.0$ to 144.6$)$ \\
\hline 1 & 195 & $95.2(-14.7$ to 205.1$)$ & $59.5(-47.1$ to 166.1$)$ & $24.4(-80.6$ to 129.5$)$ & $31.4(-73.5$ to 136.2$)$ \\
\hline $2-4$ & 553 & $71.9(-8.1$ to 151.8$)$ & $13.5(-64.6$ to 91.6$)$ & $-8.2(-85.2$ to 68.7$)$ & $4.3(-72.8$ to 81.4$)$ \\
\hline$\geqslant 5$ & 433 & $143.1(57.8$ to 228.5$)$ & $58.2(-25.9$ to 142.3$)$ & $18.5(-64.7$ to 101.7$)$ & $29.7(-53.6$ to 112.9$)$ \\
\hline Test for trend ${ }^{\star}$ & & $\mathrm{p}=0.012$ & $\mathrm{p}=0.616$ & $\mathrm{p}=0.827$ & $\mathrm{p}=0.918$ \\
\hline \multicolumn{6}{|c|}{ Apples (no. of apples per week) } \\
\hline None & 645 & 0 (baseline) & 0 (baseline) & 0 (baseline) & 0 (baseline) \\
\hline 1 & 270 & $97.1(3.2$ to 191.0$)$ & $75.7(-15.7$ to 167.1$)$ & $49.3(-40.9$ to 139.5$)$ & $44.5(-45.4$ to 134.5$)$ \\
\hline $2-4$ & 753 & $159.9(90.2$ to 229.5$)$ & $102.9(34.6$ to 171.1$)$ & $84.7(17.2$ to 152.1$)$ & $88.0(20.8$ to 155.3$)$ \\
\hline$\geqslant 5$ & 433 & $291.8(211.2$ to 372.4$)$ & $185.7(104.9$ to 266.5$)$ & $146.6(66.5$ to 226.8$)$ & $138.1(58.1$ to 218.1$)$ \\
\hline Test for trend $\dagger$ & & $\mathrm{p}<0.001$ & $\mathrm{p}<0.001$ & $\mathrm{p}<0.001$ & $\mathrm{p}<0.001$ \\
\hline
\end{tabular}

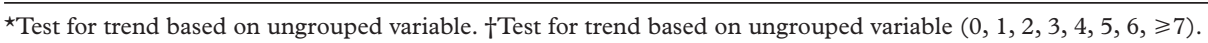


Table 3 Cross sectional analysis: differences in forced expiratory volume in one second (FEV) in ml associated with increases in the number of apples eaten per week at phase I (from no apples per week) within smoking categories ${ }^{\star}$

\begin{tabular}{|c|c|c|c|c|c|c|c|c|c|}
\hline \multirow[t]{2}{*}{ Smoking group } & \multirow[t]{2}{*}{ No. } & \multicolumn{2}{|l|}{1 per week } & \multicolumn{2}{|c|}{ 2-4 per week } & \multicolumn{2}{|c|}{$\geqslant 5$ per week } & \multirow[t]{2}{*}{ Test of trend } & \multirow[t]{2}{*}{$\begin{array}{l}\text { Test of } \\
\text { heterogeneity }\end{array}$} \\
\hline & & Difference & $95 \% C I$ & Difference & $95 \% C I$ & Difference & $95 \% C I$ & & \\
\hline Never smoked & 333 & -150.3 & -398.8 to 98.3 & 16.8 & -173.9 to 207.4 & 47.9 & -149.9 to 245.8 & $\mathrm{p}=0.241$ & $\mathrm{p}=0.941$ \\
\hline Ex-smoker $\dagger$ & 625 & -19.2 & -198.4 to 160.0 & 84.6 & -50.7 to 219.8 & 108.7 & -33.8 to 251.2 & $\mathrm{p}=0.083$ & \\
\hline Cigar/pipe smoker $\ddagger$ & 227 & 113.5 & -181.5 to 408.5 & 168.3 & -27.4 to 364.0 & 132.9 & -106.1 to 372.0 & $\mathrm{p}=0.190$ & \\
\hline Current cigarette smoker & 892 & 134.6 & 4.2 to 264.9 & 102.6 & 3.6 to 201.6 & 195.0 & 54.9 to 335.1 & $\mathrm{p}=0.012$ & \\
\hline
\end{tabular}

*All associations adjusted for age, height, body mass index, social class, work exercise, leisure exercise and total calorie intake. $†$ Association adjusted for length of time since quitting smoking. ¥Association adjusted for the number of cigars smoked per day and the number of ounces of tobacco smoked per week. $\uparrow$ Association adjusted for the number of cigarettes smoked per day (mixed smokers excluded).

21.4 to 76.3 ) lower for total energy intakes one standard deviation (597 kcal/day) apart.

There was no significant association between lung function and the frequency of fatty fish consumption either before $(p=0.572)$ or after adjustment for confounders ( $\mathrm{p}=0.851$; table 2).

There was no evidence to suggest that the strong positive association observed between lung function and apple intake differed between smoking groups (never smoked, exsmoker, cigar/pipe smoker and current smoker; table 3). However, there was some suggestion that the association with vitamin $\mathrm{E}$ might be stronger among the never smoked and that the association with total energy intake might be restricted to those not currently smoking cigarettes, although in both cases the test for a statistical interaction with smoking group failed to reach significance $(\mathrm{p}=0.466, \mathrm{p}=0.111$, respectively).

When we excluded from the full Caerphilly cohort $(n=2512)$ the 244 men with only one or two $\mathrm{FEV}_{1}$ readings at phase $\mathrm{I}$, those on asthma medication $(\mathrm{n}=74)$, and those taking vitamin supplements that might contain vitamins $A, C$ or $E(n=48)$, the associations between lung function and apples, vitamin $\mathrm{E}$, and vitamin $C$ were little changed $(p<0.001, p$ $=0.024, \mathrm{p}=0.076$, respectively). The inverse association between lung function and total energy persisted $(p=0.013)$ although the magnitude of the estimated fall in maximum $\mathrm{FEV}_{1}$ across an increase in energy intake of one standard deviation was reduced from $48.8 \mathrm{ml}$ to $35.5 \mathrm{ml}$.

LONGITUDINAL ANALYSIS

The number of apples per week and intakes of vitamin $\mathrm{E}$ and vitamin $\mathrm{C}$ were investigated further in a longitudinal analysis. Change in lung function between phase I and phase II was not significantly associated with change in any of these three dietary factors, either before or after adjustment for confounders. The coefficients for apple consumption did tend to go in the hypothesised direction, suggesting that eating more than two extra apples per week compared with no change was associated with a $16.7 \mathrm{ml}$ (95\% CI -36.1 to 69.5$)$ reduction in decline in lung function (table 4), but the trend was weak as well as non-significant $(\mathrm{p}=0.174)$ and became slightly weaker $(\mathrm{p}=0.184)$ after additional adjustment for average apple consumption. The coefficients for vitamin $\mathrm{E}$ and vitamin C went in the opposite direction to that hypothesised.

Average apple consumption was significantly $(p=0.004)$ associated with change in lung function between phases suggesting that eating five or more apples per week compared with none was associated with a decrease in lung function decline of $74.1 \mathrm{ml}$ (95\% CI 17.7 to 130.6) over five years (table 4). However, after adjustment for confounders the magnitude of the association decreased markedly, suggesting only a $47.7 \mathrm{ml}(95 \% \mathrm{CI}-10.7$ to 106.2$)$ reduction and lost statistical significance $(\mathrm{p}=0.098$;

Table 4 Longitudinal analysis: change in forced expiratory volume in one second (FEV) over five years and its association with change in apple intake and average apple consumption over the same period

\begin{tabular}{|c|c|c|c|c|c|c|c|c|c|}
\hline & \multirow[t]{3}{*}{ No. } & \multicolumn{8}{|c|}{ Additional change in $F E V_{1}$ compared with change at baseline adjusted for: } \\
\hline & & \multicolumn{2}{|c|}{$\begin{array}{l}\text { (1) Age, height, age and } \\
\text { height }^{2}\end{array}$} & \multicolumn{2}{|c|}{$\begin{array}{l}\text { (2) Model } 1+\text { body mass index } \\
\text { and smoking }\end{array}$} & \multicolumn{2}{|c|}{$\begin{array}{l}\text { (3) Model } 2+\text { social class, work } \\
\text { exercise and leisure exercise }\end{array}$} & \multicolumn{2}{|c|}{$\begin{array}{l}\text { (4) Model } 3 \text { plus total energy } \\
\text { intake }\end{array}$} \\
\hline & & $\begin{array}{l}\text { Additional } \\
\text { change in } \\
F E V_{1}\end{array}$ & $95 \% C I$ & $\begin{array}{l}\text { Additional } \\
\text { change in } \\
F E V_{1}\end{array}$ & $95 \% C I$ & $\begin{array}{l}\text { Additional } \\
\text { change in } \\
F E V_{1}\end{array}$ & $95 \% C I$ & $\begin{array}{l}\text { Additional } \\
\text { change in } \\
F E V_{1}\end{array}$ & $95 \% C I$ \\
\hline \multicolumn{10}{|c|}{$\begin{array}{l}\text { Change in the no. of apples } \\
\text { eaten per week }{ }^{\star}\end{array}$} \\
\hline Decrease $>2$ & 249 & -21.9 & -76.6 to 32.9 & -25.5 & -79.7 to 28.7 & -23.5 & -77.5 to 30.5 & -23.2 & -77.3 to 30.9 \\
\hline Decrease $\leqslant 2$ & 244 & -6.2 & -61.3 to 49.0 & -10.2 & -64.7 to 44.4 & -6.3 & -60.7 to 48.1 & -6.2 & -60.7 to 48.2 \\
\hline No change & 579 & 0 & Baseline & 0 & Baseline & 0 & Baseline & 0 & Baseline \\
\hline Increase $\leqslant 2$ & 242 & -12.4 & -67.7 to 43.0 & -25.6 & -80.6 to 29.5 & -20.8 & -75.7 to 34.1 & -20.5 & -75.5 to 34.4 \\
\hline Increase $>2$ & 278 & 17.5 & -35.3 to 70.3 & 14.2 & -38.6 to 67.0 & 16.5 & -36.3 to 69.2 & 16.7 & -36.1 to 69.5 \\
\hline Test for trend $\dagger$ & & $\mathrm{p}=0.136$ & & $\mathrm{p}=0.164$ & & $\mathrm{p}=0.175$ & & $\mathrm{p}=0.174$ & \\
\hline \multicolumn{10}{|c|}{ Average apple consumption (no. per week) } \\
\hline$<1$ & 401 & 0 & Baseline & 0 & Baseline & 0 & Baseline & 0 & Baseline \\
\hline 1 & 281 & -39.6 & -95.6 to 16.4 & -44.4 & -100.0 to 11.2 & -41.3 & -96.7 to 14.2 & -41.3 & -96.7 to 14.2 \\
\hline $2-4$ & 633 & 47.0 & 1.0 to 92.9 & 25.7 & -21.1 to 72.5 & 31.3 & -15.5 to 78.1 & 31.9 & -15.0 to 78.8 \\
\hline$\geqslant 5$ & 277 & 74.1 & 17.7 to 130.6 & 37.7 & -20.5 to 95.9 & 46.3 & -11.9 to 104.4 & 47.7 & -10.7 to 106.2 \\
\hline Test for trend $\ddagger$ & & $\mathrm{p}=0.004$ & & $\mathrm{p}=0.200$ & & $\mathrm{p}=0.108$ & & $\mathrm{p}=0.098$ & \\
\hline
\end{tabular}

${ }^{\star}$ Difference (phase II—phase I) multiplied by 5 and divided by length of follow up. $†$ Test for trend based on ungrouped variable. $\ddagger$ Test for trend based on ungrouped frequency variable. 
table 4). Additional adjustment for change in apple consumption had little effect. Associations with average vitamin $\mathrm{C}$ and vitamin $\mathrm{E}$ intake were also positive but failed to reach statistical significance either before or after adjustment for confounders.

\section{Discussion}

APPLES

In a large prospective study of middle aged Welshman we found a strong cross sectional positive association between the number of apples eaten per week and lung function as measured by maximum $\mathrm{FEV}_{1}$. After adjusting for confounders including body mass index, smoking history, social class, work exercise, leisure exercise, and total energy intake, in addition to age and height, model coefficients suggested that lung function was $138 \mathrm{ml}(95 \%$ CI 58 to 218) higher for those eating five or more apples per week compared with nonconsumers. This finding is consistent with results from other large epidemiological studies $^{6}{ }^{14}{ }^{15}$ which have reported positive associations between lung function and the consumption of fresh fruit.

It has been hypothesised that the observed association between lung function and fresh fruit intake is due to the antioxidant vitamin $\mathrm{C},{ }^{169}$ but our study provided little evidence of this. After adjustment for confounders, initially positive associations between lung function and other food sources rich in vitamin $\mathrm{C}$-namely, fruit juices/squashes and citrus fruit-lost statistical significance $(p=0.918$ and $p=0.393$, respectively). Furthermore, the association between lung function and apples appeared to be independent of both vitamin $\mathrm{C}$ and vitamin $\mathrm{E}$ intake. It is possible that apples may be acting as a marker for a more healthy diet, although additional adjustment for the frequency of green vegetable/salad consumption had little if any effect on the results presented for apples in table 2 (data not shown). When reporting an inverse association between hard fruit and chronic non-specific lung disease in elderly men in the Zutphen study, ${ }^{16}$ the antioxidant effects of flavonoids such as quercetin were suggested as a possible mechanism. Quercetin is found in high concentrations in apples, onions, tea, and red wine $^{24}$ and may therefore help to explain our findings in Caerphilly.

\section{VITAMIN E}

In our preliminary analysis we found a significant positive association between lung function and vitamin $\mathrm{E}$ but this appeared to be explained by smoking and social class, both of which were positive confounders. However, when additional adjustment was made for total energy intake, the coefficient for vitamin $\mathrm{E}$ almost tripled and regained statistical significance $(\mathrm{p}<0.01)$ with lung function estimated to be $39 \mathrm{ml}$ (95\% CI 9 to 69) higher for vitamin $\mathrm{E}$ intakes one standard deviation ( $2 \mathrm{mg}$ /day) apart. A significant $(\mathrm{p}<0.001)$ positive association was also observed between lung function and the ratio of vitamin $\mathrm{E}$ to total fat intake, even after adjustment for age, height, body mass index, smoking, social class, and exercise (data not shown). Any effect of vitamin E may therefore depend on the relative rather than the absolute amount in the diet, a possible reflection of the positive association that is known to exist between vitamin $\mathrm{E}$ requirement and the dietary intake of polyunsaturated fatty acid. $^{25}$

Positive associations between lung function and dietary vitamin $\mathrm{E}$ have been reported previously by Dow et $a l^{10}$ in a small survey of elderly men and women and by Britton et $a l^{7}$ in a large random sample of the Nottingham adult population. A negative association between vitamin $\mathrm{E}$ and diagnosed asthma reported by the Nurses Health Study ${ }^{26}$ may have been inflated by the avoidance of peanuts among asthmatics. A similar explanation cannot be levelled here as the dietary questionnaire on which vitamin $\mathrm{E}$ intake was assessed did not collect any information on peanuts or nuts which were rarely eaten in this population. ${ }^{20}$ The association also appeared to be independent of vitamin $\mathrm{C}$ intake. Another possible explanation is that this is one spurious result out of nine significance tests. Bonferroni's correction suggests that, with nine significance tests, we should use $p<0.0055$ as the cut off for statistical significance rather than $\mathrm{p}<0.05$, although this is a highly conservative approach. ${ }^{27}$

\section{TOTAL ENERGY INTAKE}

The strong inverse association observed between lung function and energy intake, though unexpected, appeared to be independent of body mass index. This suggested that it could not be explained in terms of reduced lung function with increasing obesity, although there is still the possibility that lung function depends on aspects of body fatness not well measured by body mass index and that energy intake is simply acting as a marker for these. Whether it is then appropriate to adjust all our analyses for energy intake is debatable. It is clear that, without adjustment, observed associations may simply reflect the effects of other nutrients. However, to adjust may be an over-adjustment helping to mask a real association that depends on the absolute amount in the diet rather than the relative amount. This makes it difficult to interpret not only our results for vitamin $\mathrm{E}$ but also those for magnesium. However, the strong negative association observed between lung function and magnesium prior to adjustment for energy intake was in the opposite direction to that hypothesised, making confounding by energy intake a plausible explanation.

\section{FATTY FISH}

Our failure to demonstrate a positive association between the frequency of eating fatty fish and lung function is in contrast to results from the Second National Health and Nutrition Examination Survey (NHANES II) ${ }^{28}$ which reported an inverse association between wheeze and dietary fish, and to results from studies of Australian children, ${ }^{29} 30$ one of which reported an odds ratio for current asthma by 
diet, with or without oily fish, of 0.26 (95\% CI 0.09 to 0.72$).^{30}$ However, there was no evidence of an inverse association between diagnosed asthma and omega- 3 fatty acids in the American Nurses Health Study ${ }^{26}$ and studies of asthmatics treated with fish oil have provided little evidence of any beneficial effect. ${ }^{31-33}$

PREDICTING DECLINE IN LUNG FUNCTION

Several studies have reported cross sectional associations between fresh fruit or antioxidant vitamins and lung function in both children ${ }^{15}$ and adults, ${ }^{5-13}$ but only one other study has so far looked at the longitudinal effects of change in diet on decline in lung function. Carey et al, ${ }^{14}$ reporting on data from successive health and lifestyle surveys, found a strong association between increasing fresh fruit consumption over time and reduced lung function decline. The lack of an independent association with average fresh fruit consumption over the same period led them to hypothesise that the protective effect of fresh fruit was totally reversible rather than progressive. In our longitudinal analysis we found no support for this hypothesis. Average apple consumption and change in apple consumption appeared to increase with increasing lung function, although neither association was statistically significant after adjustment for confounders. There was no evidence of an association between change in vitamin $\mathrm{E}$ or vitamin $\mathrm{C}$ intake over five years and decline in lung function over the same period.

\section{DIETARY DATA}

Our failure to demonstrate significant positive associations for vitamin $C$ and $\beta$-carotene with lung function may be due to the way in which these nutrients were estimated, since misclassification of nutrient intakes tends to bias associations towards the null. ${ }^{34}$ Significant associations reported between vitamin $\mathrm{C}$ and lung function by studies using food frequency questionnaires $^{71012}$ tend to be small and not inconsistent with our own estimate of $26 \mathrm{ml}$ (95\% CI -5 to 54 ) per standard deviation vitamin C (table 1). One possible reason for nutrient misclassification in phase $I$ is that the dietary questionnaire did not ask about the frequency of eating tinned fruit, although this was rectified in phase II. Changes in the food frequency questionnaire between phases might also help to explain the lack of an association longitudinally between decline in lung function and changes in vitamin intake.

These problems were not shared to the same extent by our food frequency variables which were simply responses to single questions on the dietary questionnaire. For apples the question was essentially the same at both phasesthat is, "number of apples eaten per week (please specify)" at phase I and "how many apples do you eat per week?" at phase II - providing suitably comparable data for a longitudinal analysis. The ability of Hertog et $a l^{35}$ to demonstrate a strong inverse relationship between digestive cancer and fruit and vegetable consumption at phase I provides further evidence for the validity of our information on apples and citrus fruit.

CONCLUSION

We have demonstrated a positive cross sectional association between lung function and the number of apples eaten per week in a cohort of middle aged Welshmen. This association appeared to be independent of vitamin $\mathrm{E}$ and vitamin $\mathrm{C}$ intakes and may therefore be explained by other antioxidant constituents of apples such as flavonoids (e.g. quercetin). The recent suggestion that such effects are reversible was not supported by our longitudinal analysis.

We would like to thank the men of Caerphilly for participating in the study and the MRC Epidemiology Unit staff for collecting and providing access to the data. We would also like to than Professor David Strachan (St George's Hospital Medical School) and Mr Peter Sweetnam (MRC Epidemiology Unit) for reading and commenting on earlier drafts of the paper.

Sources of funding: Data collection funded by MRC.

1 Seaton A, Godden DJ, Brown K. Increase in asthma: a more toxic environment or a more susceptible population? toxic environment or

2 Chatham MD, Eppler JH, Sauder LR, et al. Evaluation of the effects of vitamin $\mathrm{C}$ on ozone-induced bronchoconstriction in normal subjects. Ann NY Acad Sci 1987;498: 269-79.

3 Mohsenin V. Effect of vitamin $\mathrm{C}$ on $\mathrm{NO}_{2}$-induced airway hyperresponsiveness in normal subjects. A randomised double-blind experiment. Am Rev Respir Dis 1987;136: 1408-11

4 Anderson R, Theron AJ, Ras GJ. Regulation by the antioxidants ascorbate, cysteine, and dapsone of the increased extracellular and intracellular generation of reactive oxidants by activated phagocytes from cigarette smokers. $A m$ Rev Respir Dis 1987;135:1027-32.

5 Bodner C, Seaton A, Godden D. Plasma vitamin C, lung function and adult onset wheeze: A case control study. Eur Respir f 1997;10(Suppl 25):17S.

6 Strachan DP, Cox BD, Erzinclioglu SW, et al. Ventilatory function and winter fresh fruit consumption in a random function and winter fresh fruit consumption in

7 Britton JR, Pavord ID, Richards KA, et al. Dietary antioxidant vitamin intake and lung function in the general population. Am F Respir Crit Care Med 1995;151:1383-7.

8 Schwartz J, Weiss ST. Relationship between dietary vitamin $\mathrm{C}$ intake and pulmonary function in the First National Health and Nutrition Examination Survey (NHANES I) Am f Clin Nutr 1994;59:110-4.

9 Ness AR, Khaw KT, Bingham S, et al. Vitamin C status and respiratory function. Eur 7 Clin Nutr 1996;50:573-9.

10 Dow L, Tracey M, Villar A, et al. Does dietary intake of vitamins $\mathrm{C}$ and $\mathrm{E}$ influence lung function in older people? $\mathrm{Am}$ mins C and E influence lung function in

$11 \mathrm{Hu} \mathrm{G}$, Zhang X, Chen J, et al. Dietary vitamin C intake and lung function in rural China. Am 7 Epidemiol 1998;148: 594-9.

12 Grievink L. Antioxidants and air pollution in relation to indicators of asthma and COPD. Wageningen: Grafisch Service Centrum van Gils BV, 1998

13 Chuwers P, Barnhart S, Blanc P, et al. The protective effect of $\beta$-carotene and retinol on ventilatory function in an asbestos-exposed cohort. Am f Respir Crit Care Med 1997; 155:1066-71.

14 Carey IM, Strachan DP, Cook DG. Effects of changes in fresh fruit consumption on ventilatory function in healthy British adults. Am f Respir Crit Care Med 1998;158:728-33.

15 Cook DG, Carey IM, Whincup PH, et al. Effect of fresh fruit consumption on lung function and wheeze in children. Thorax 1997;52:628-33.

16 Miedema I, Feskens EJM, Heederik D, et al. Dietary determinants of long-term incidence of chronic nonspecific lung diseases. The Zutphen study. Am f Epidemiol 1993;138:3745.

17 Black PN, Sharpe S. Dietary fat and asthma: is there a connection? Eur Respir F 1997;10:6-12.

18 Hill JM, Britton J. Effect of intravenous magnesium sulphate on airway calibre and airway reactivity to histamine in asthmatic subjects. Br f Clin Pharmacol 1996;42:629-31.

19 Britton J, Pavord I, Richards K, et al. Dietary magnesium, lung function, wheezing and airway hyperreactivity in random adult population sample. Lancet 1994;344:357-62.

20 MRC Epidemiology Unit. The Caerphilly collaborative heart disease studies: project description and manual of operations. disease studies: project description and mant

21 Office of Population Censuses and Surveys. Classification of occupations and coding index. London: HMSO, 1980.

22 Yarnell JWG, Fehily AM, Milbank JE, et al. A short dietary questionnaire for use in an epidemiological survey: comparison with weighed dietary records. Hum Nutr App Nutr 1983;37A:103-12. 
23 Stata Corporation. Stata reference manual: release 3.1, 6th edition. College Station, Texas: Stata Corporation, 1993.

24 Gross M, Pfeiffer M, Martini M, et al. The quantitation of metabolites of quercetin flavonols in human urine. Cancer Epidemiol Biomarkers Prevent 1996;5:711-20

25 Department of Health. Dietary reference values for food energy and nutrients for the United Kingdom: report on health and social subjects 41. London: HMSO, 1991.

26 Troisi RJ, Willett WC, Weiss ST, et al. A prospective study of diet and adult-onset asthma. Am f Respir Crit Care Med 1995;151:1401-8.

27 Bland JM, Altman DG. Multiple significance tests: the Bonferroni method. BMF 1995;310:170.

28 Schwartz J, Weiss ST. Dietary factors and their relation to respiratory symptoms. The Second National Health and Nutrition Examination Survey. Am f Epidemiol 1990;132:67-76.

29 Peat JK, Salome CM, Woolcock AJ. Factors associated with bronchial hyperresponsiveness in Australian adults and children. Eur Respir f 1992;5;921-9.
30 Hodge I, Salome CM, Peat JK, et al. Consumption of oily fish and childhood asthma risk. Med f Aust 1996;164:13740.

31 Kirsch CM, Payan DG, Wong MYS, et al. Effect of eicosapentaenoic acid in asthma. Clin Allergy 1988;18:177-87.

32 Arm JP, Horton CE, Mencia-Huerta J-M, et al. Effect of dietary supplementation with fish oil lipids on mild asthma Thorax 1988;43:84-92.

33 Thien FCK, Mencia-Huerta J-M, Lee TH. Dietary fish oil effects on seasonal hay fever and asthma in pollen-sensitive subjects. Am Rev Respir Dis 1993;147:1138-43.

34 Freudenheim JL, Johnson NE, Wardrop RL. Nutrient misclassification: bias in the odds ratio and loss of power in the Mantel test for trend. Int 7 Epidemiol 1989;18:232-8.

35 Hertog MGL, Bueno-de-Mesquita HB, Fehily AM, et al. Fruit and vegetable consumption and cancer mortality in the Caerphilly study. Cancer Epidemiol Biomarkers Prevent 1996;5:673-7. 